\title{
KAJIAN FILSAFAT PANCASILA DALAM \\ PENDIDIKAN MLTIKULTURAL DI INDONESIA
}

\section{Herly Jenet Lesilolo}

\begin{abstract}
Multicultural education in Indonesia, in principle, to instill confidence that the diversity of cultures that exist in Indonesia is a gift that should be awarded in the sense of unity, solidarity and sympathy. That in diversity there is life in harmony and in doing good to fellow human beings in diversity. Society in a multicultural context sailed to live in diversity, build mutual trust (mutual trust), maintain mutual understanding (mutual understanding), and uphold mutual respect.Upholding tolerance as the embodiment recognizes and respects human rights. Is a concrete manifestation of life in multicultural is each individual recognizes the relationship between human beings built on fraternity and brotherhood among human compatriots. Furthermore sense of unity, solidarity and sympathy in education is expected to empower individuals or groups to build a life in the human environment bersesama, love peace and build a future that is united in diversity. United in diversity for the people of Indonesia may be more critical imbued with the philosophy of Pancasila as the nation of Indonesia. Pancasila is believed to have norms and values that are true, fair, and wise. The specificity of norms and values of Pancasila which is believed to be inherent in the values of divinity, humanity, unity, democracy, and social justice as a whole. In line with the principle of the Pancasila multicultural education has a strong synergy with multicultural education because both interpret diversity in berketuhanan value, which is humane, the berpersatuan, which berkerakyatan and social justice.
\end{abstract}

Keywords : philosophy of Pancasila, multicultural education

\begin{abstract}
Abstrak
Pendidikan multikultural di Indonesia pada prinsipnya menanamkan keyakinan bahwa keragaman budaya yang ada di Indonesia adalah anugerah yang patut mendapat penghargaandalam rasa kesatuan, kebersamaan dan simpati.Bahwa dalam keberagaman terdapat kehidupan yang selaras dan berbuat baik terhadap sesama manusia dalam keberagaman. Masyarakat dalam konteks multikultural berlajar hidup dalam perbedaan, membangun saling percaya (mutual trust), memelihara saling pengertian (mutual understanding), dan menjunjung sikap saling menghargai.Menjunjung sikaptoleransi sebagai perwujudan mengakui dan menghormati hak-hak asasi manusia. Wujud secara kongkrit kehidupan dalam multikultural adalah setiap individu mengakui relasi antara sesama manusia dibangun berdasarkan persaudaraan sebangsa dan persaudaraan sesama manusia. Lebih jauh lagi rasa kesatuan, kebersamaan dan simpati dalam pendidikan diharapkan dapat memberdayakan individu atau kelompok membangun kehidupan dalam
\end{abstract}


lingkungan manusia bersesama, cinta damai dan membangun sebuah masa depan yang bersatu dalam keberagaman.Bersatu dalam keberagaman bagi masyarakat Indonesia dapat lebih dijiwai secara kritis melalui Pancasila sebagai falsafah bangsa Indonesia.Pancasila diyakini memiliki norma-normadan nilai-nilai yang benar, adil, dan bijaksana. Kekhasan norma dan nilai yang diyakini melekat dalam Pancasilayaitunilai-nilai ketuhanan, kemanusiaan, persatuan, kerakyatan, dan keadilan sosial sebagai satu kesatuan. Sejalan dengan prinsip pendidikan multikultural maka Pancasila memiliki sinergi yang kuat dengan pendidikan multikultural karena sama-sama memaknai keberagaman dalam nilai yang berketuhanan, yang berkemanusiaan, yang berpersatuan, yang berkerakyatan dan yang berkeadilan sosial.

Kata kunci : filsafat Pancasila, pendidikan multikultural

\section{PENDAHULUAN}

Bumi Indonesia sampai saat ini masih dikukuhkan sebagai salah satu negara yang multikultural terbesar di dunia. Kenyataan ini dapat dilihat dari kondisi geografis alam dan demografis yang begitu beragam dan luas. Keragaman yang dimiliki Indonesia, di satu sisi adalah merupakan anugerah yang sangat berharga dan harus dilestarikan, akan tetapi keragaman ini di sisi lain diakui atau tidakadalah sebuah tantangan karena di dalamnya akan dapat menimbulkan berbagai persoalan, seperti kolusi sesama etnis, nepotisme, kemiskinan, perusakan lingkungan, separatisme, dan yang lebih menguatirkan adalah akan hilangnya rasa kemanusiaan untuk menghormati hak-hak orang lain, yang merupakan bentuk nyata sebagai bagian dari multikulturalisme tersebut.

Sebagai bangsa yang memiliki kekayaan budaya, Indonesia sangat membutuhkan perdamaian, keadilan, persamaan, persatuan, demokrasi, toleransidanreligiusitas yang merupakan unsur yang dapat dilahirkan oleh pendidikan multikultural. Tetapi, patut dicatat bahwa akhir-akhir ini yang terjadi justru jauh dari harapan kemanusiaan yang mengedepankan nilai-nilai keadilan sosial, keharmonisan, keamanan, perdamaian, dan persaudaraan. Dengan kata lain diskriminasi agama, etnis, politik, ekonomi, budaya dan pendidikan, semakin menggurita di Indonesia.

Kondisi seperti ini, sebagai bangsa, Indonesia dituntut untuk mampu merekonstruksi kebudayaan nasional yang dapat menjadi perekat atau integrating 
force terhadap keragaman dan heterogenitas kehidupan sosial budaya. Dibutuhkan kearifan untuk menerima perbedaan yang mau tidak mau akan muncul ditengah pergaulan antar kelompok yang heterogen. Saling menerima, mengerti dan menghargai perbedaan adalah nilai sosial yang mutlak harus dimiliki agar tidak terbawa pada perpecahan dan pertikaian disamping harus juga menghindari egoisme golongan tertentu. Kemampuan untuk memikirkan, membicarakan dan memecahkan persoalan yang muncul dari perbedaan secara terbuka, rasional dan damai haruslah ditanamkan kepada masyarakat sejak dini.

Sikap saling menerima, menghargai nilai, budaya, keyakinan yang berbeda tidak otomatis akan berkembang sendiri. Apalagi karena dalam diri seseorang ada kecenderungan untuk mengharapkan orang lain menjadi seperti dirinya. Sikap saling menerima dan menghargai akan cepat berkembang bila dilatihkan dan dididikkan pada generasi muda dalam sistem pendidikan nasional.Dengan pendidikan, sikap penghargaan terhadap perbedaan yang direncana baik, generasi muda dilatih dan disadarkan akan pentingnya penghargaan pada orang lain dan budaya lain bahkan melatihnya untukmenerimakeberagamandalam hidup sebagaisuatuanugerah yang tidakmungkindipaksakanuntukdiseragamkan sehingga sewaktu dewasa merekasudah mempunyai mencintaidanmenghargaiperbedaan.

Pancasila sebagai falsafah bangsa Indonesia, memiliki integrating force yang mampu menciptakan kehidupan bangsa Indonesia yang multikutural. Sikap saling menerima, menghargai nilai, budaya, keyakinan yang berbeda tidak otomatis akan berkembang sendiri. Apalagi karena dalam diri seseorang ada kecenderungan untuk mengharapkan orang lain menjadi seperti dirinya. Pendidikan multikultural yang dikaji melalui filsafat Pancasila dapat dimaknai sebagai proses untuk menumbuhkan kemampuan cara hidup menghormati, tulus, dan toleran terhadap keragaman budaya yang hidup di tengah-tengah masyarakat plural. Diharapkan adanya kekenyalan dan kelenturan mental bangsa menghadapi benturan konflik sosial, sehingga persatuan bangsa tidak mudah patah dan tercabik. 


\section{FILSAFAT PANCASILA}

Filsafat adalah pengetahuan dan penyelidikan dengan akal budi mengenai hakikat segala yang ada, sebab, asal, dan hukumnya. Istilah 'filsafat' secara etimologis merupakan padanan kata falsafah (Arab) dan philosophy (Inggris) yang

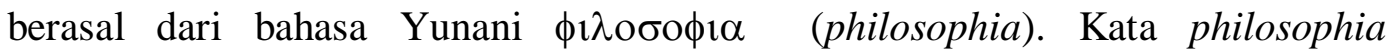
merupakan kata majemuk yang tersusun dari kata philos atau philein yang berarti kekasih, sahabat, mencintai dan kata sophia yang berarti kebijaksanaan, hikmat, kearifan, pengetahuan. ${ }^{1}$

Menurut batasan moderen, filsafat diartikan antara lain, sebagai ilmu yang berusaha untuk memahami semua hal yang timbul di dalam keseluruhan lingkup manusia. Dengan ini diharapkan agar manusia dapat mengerti dan mempunyai pandangan menyeluruh dan sistematis mengenai alam semesta dan posisi manusia di dalamnya. Yang dimaksud dengan di dalamnya di sini adalah bahwa manusia itu merupakan kesatuan dari dunia. Dengan adanya manusia tentu manusia mempunyai caranya berada ${ }^{2}$

Melalui batasan-batasan mengenai filsafat di atas, maka filsafat menuntut manusia selalu bisa berpikir mengenai keadaan alam. Manusia seharusnya memiliki pengetahuan mengenai keberadaannya, dan lebih dari itu filsafat mengharapkan manusia dapat memaknai segala sesuatu dibalik dari pengetahuan atau pengalaman sebagai jawaban terhadap keadaan di mana manusia itu berada. Itu artinya manusia seharusnya dapat memaknai gejala yang dijumpai dalam konteks hidupnya sebagai sesuatu yang tidak ada dan menjadi ada, melalui pengetahuan yang dimiliki.

Mencermati pengertian filsafat di atas, maka filsafat Pancasila juga perlu didefenisikan sesuai dengan filsafat. Bahwa pembahasan secara filsafat adalah membahas Pancasila pada makna dan pengertian yang sedalam-dalamnya. Termasuk penting untuk memahami apa yang ada dibalik makna Pancasila dan memiliki pengetahuan terhadap Pancasila sebagai suatu kesatuan, yang memiliki sistem pemikiran rasional, sistematis, terdalam dan menyeluruh. Ada empat 
macam sebab (causa) yang menurut Notonagoro dapat digunakan untuk menetapkan Pancasila sebagai Dasar Filsafat Negara, yaitu sebab berupa materi (causa material), sebab berupa bentuk (causa formalis), sebab berupa tujuan (causa finalis), dan sebab berupa asal mula karya (causa eficient $)^{3}$ Demikian juga untuk memahami pengetahuan Pancasila, dapat dipahami dari hakikat Pancasila itu sendiri. Memahami filsafat Pancasila memerlukan juga kajian dari hakikat bangsa dan negara Indonesia, dari nilai-nilai masyarakat Indonesia dan digali dari bangsa Indonesia sendiri.

Dalam mengkaji filsafat Pancasila, maka perlu untuk membahas Pancasila dari cabang filsafat yaitu,ontologi Pancasila, Epistemologi Pancasila dan Aksiologi Pancasila. Ontologi Pancasila, Ontology atau onlogi berasal dari kata ononthos (being) artinya "yang ada" Ontologi adalah ilmu pengetahuan tentang "yang ada" sebagai yang ada, hakekatsebenarnya tentang "yang ada" atau hakekat suatu obyek. Ontologi Pancasila, adalah sesuatu yang ada. Manusia harus membuat dan meng-ada-kan Pancasila itu dalam berbagai pengalaman hidup. Pancasila harus diuji keserasian supaya bereksistensi. Pancasila perlu diuji dengan pengalaman,artinya Pancasila sebagai obyek material dapat dipercaya keberadaannya jika manusia mengalami sendiri makna Pancasila. Penting dalam keserasian memaknai Pancasila dalam setiap pengalaman dalam tangkapan inderawi seseorang perlu serasi dengan tangkapan inderawi orang lain. Pancasila menjadi sesuatu yang bereksistensi (existence), artinya dialami secara inderawi pada tempat dan waktu tertentu. Yang bereksistensi adalah nyata dan ada, namun "yang ada" tidak harus bereksistensi'. Manusia memiliki peranan penting dalam ontologi Pancasila. Dengan Pancasila sebagai "Yang Ada" dapat bereksistensi. ${ }^{4}$

Mengkaji sejarah dan pengertian Pancasila terhadap ontologi Pancasila, maka Pancasila disebut sebagai "Yang Ada". "Yang Ada" dalam Pancasila adalah memiliki sifat segala sesuatu atau ciri yang melekat pada apa saja. "Yang ada" pada Pancasila adalah menerapkan ciri yang sama yang dimiliki segala sesuatu. Artinya Pancasila secara ontologis memiliki hal-hal yang mutlak, yaitu terdiri atas susunan kodrat, raga dan jiwa, jasmani dan rohani. Pancasila mutlak dengan "Yang Ada" lima nilai dasar luhur yang ada dan berkembang bersama dengan 
bangsa Indonesia. Lima nilai dasar inilah yang selanjutnya merupakan kristalisasi nilai-nilai yang diyakini kebenarannya oleh bangsa Indonesia yang menimbulkan tekad untuk mewujudkan nilai-nilai tersebut dalam sikap tingkah laku dan perbuatan. Bahwa Pancasila dilahirkan dalam tiga hal yaitu niai-nilai adat istiadat serta kebudayaan dan nilai-nilai religius. ${ }^{5}$

Epistemologi Pancasila, Secara epistemologis kajian Pancasila sebagai filsafat dimaksudkan sebagai upaya untuk mencari hakikat Pancasila sebagai suatu sistem pengetahuan. Sebagai suatu sistem pengetahuan maka Pancasila harus diperoleh maknanya melalui, pengalaman dan akal sehat. Keutuhan Pancasila sebagai suatu sistem pengetahuan tidak akan diperoleh, jika manusia tidak berperan dalam pengalaman dan menggunakan pengalaman itu dengan logika (akal sehat). Menjadi bagian yang utuh manusia dan Pancasila sebagai sistem pengetahuan. Menemukan Pancasila dalam pengetahuan harus dengan menyimpulkan sesuatu berdasarkan pengalaman. Pengetahuan tentang Pancasila tentunya dapat diperoleh melalui perantaraan panca indera, secara empiris atau berpikir induktif.

Sebagai pengetahuan empiris Pancasila dapat salah akibat keterbatasan kemampuan indera manusia. Fakta yang diperoleh tentang Pancasila tidak dapat digeneralisasi dan fakta itu seringkali hanya berupa kumpulan fakta belaka. Akibatnya tidak dapat dihindari bahwa penggunaan rasio menyebabkan pengetahuan tentang Pancasila dapat bersifat subyektif, maksudnya kebenaran Pancasilaitu sendiri bisa dipandang dari sudut pandang orang yang menyatakannya. Pancasila menjadi benar atau tidak itu sangat bergantung pada manusia membenarkan Pancasila itu menurut dirinya sendiri.

Secara epistemologis kajian Pancasila sebagai filsafat dimaksudkan sebagai upaya untuk mencari hakikat Pancasila sebagai suatu sistem pengetahuan. Pancasila sebagai sistem filsafat pada hakikatnya juga merupakan sistem pengetahuan. Ini berarti Pancasila telah menjadi suatu belief system, sistem citacita, menjadi suatu ideologi. Oleh karena itu Pancasila harus memiliki unsur rasionalitas terutama dalam kedudukannya sebagai sistem pengetahuan. 
Aksiologi Pancasila, Istilah aksiologi berasal dari kata Yunani axios yang artinya nilai, manfaat, dan logos yang artinya pikiran, ilmu atau teori. Aksiologi adalah teori nilai, yaitu sesuatu yang diinginkan, disukai atau yang baik. Bidang yang diselidiki adalah hakikat nilai, kriteria nilai, dan kedudukan metafisika suatu nilai. Nilai (value dalam Inggris) berasal dari kata Latin valere yang artinya kuat, baik, berharga. Dalam kajian filsafat merujuk pada sesuatu yang sifatnya abstrak yang dapat diartikan sebagai "keberhargaan" (worth) atau "kebaikan" (goodness). Nilai itu sesuatu yang berguna. Nilai juga mengandung harapan akan sesuatu yang diinginkan. ${ }^{6}$

Pancasila memiliki nilai berbentuk esensi logis yang diketahui melalui akal, tidak terdapat dalam ruang dan waktu (pendekatan obyektivisme logis). Ini sesuai dengan pendapat John Dewey yang menyatakan bahwa nilai adalah perbuatan memberi nilai, menyangkut tindakan akal untuk melakukan generalisasi ilmiah. Ada nilai yang memang sudah melekat dengan Pancasila. Satu sisi, Pancasila adalah sesuatu yang benar-benar bernilai. Memiliki nilai hakiki atau sesuatu yang sejak semula sudah mempunyai nilai (nilai Instrinsik). Di sisi lain, Pancasila adalah sesuatu yang diberi nilai, diberi nilai buatan karena dapat dipakai sebagai sarana mencapai tujuan.

Pancasila memiliki nilai reaksi yang dapat diberikan seseorang. Keberadaan Pancasila tergantung pada pengalaman (pendekatan subyektivisme). Kemungkinan saja Pancasila bagi Indonesia juga memiliki nilai sebagai obyek kepentingan. Pancasila bernilai jika ada kepentingan terhadapnya. Itu artinya Pancasila mutlak dapat memberikan penilaian berhubungan dengan sikap, perasaan dan keinginan seseorang.

Manusia Indonesia yang berakal, seharusnya mengeksiskan Pancasila dalam pengalaman hidup. Manusia Indonesia yang memiliki pengetahuan seharusnya, membangun konteks hidup melalui pengalaman dan akal sehat. Pengalaman hidup yang berpancasila, akan semakin bermakna dan bernilai jika manusia menggunakan akal sehat dalam implementasi pengetahuannya tentang Pancasila. 


\section{PENDIDIKAN MULTIKULTURAL}

Banks mendefinisikan pendidikan multikultur sebagai berikut: "Multicultural education is a field of study and an emerging discipline whose major aim is to create equal educational opportunities for students from diverse racial, ethnic, socialclass, and cultural groups. One of its important goals is to help all students to acquire the knowledge,attitudes, and skills needed to function effectively in a pluralistic democratic society and to interact, negotiate, and communicate with peoples from diverse groups in order to create a civic and moral community that works for the common good. ${ }^{7}$

Banks yakin bahwa sebagian dari pendidikan lebih mengarah pada mengajari bagaimana berpikir daripada apa yang dipikirkan. Ia menjelaskan bahwa siswa harus diajari memahami semua jenis pengetahuan, aktif mendiskusikan konstruksi pengetahuan(knowledge construction) dan interpretasi yang berbeda-beda. Pendidikan seharusnya selalu mempelajari semua pengetahuan dan turut serta secara aktif dalam membicarakan konstruksi pengetahuan dan dalam pengetahuan diterima terdapat beraneka ragam interpretasi yang sangat ditentukan oleh kepentingan masing-masing, mungkin saja interpretasi itu nampak bertentangan sesuai dengan sudut pandangnya. Siswa harus dibiasakan menerima perbedaan.

Selanjutnya Banks berpendapat bahwa pendidikan multikultural merupakan suatu rangkaian kepercayaan ( set of beliefs ) dan penjelasan yang mengakui dan menilai pentingnya keragaman budaya dan etnis di dalam bentuk gaya hidup,pengalaman sosial, identitas pribadi, kesempatan pendidikan dari individu, kelompok maupun negara. Ia mendefinisikan pendidikan multikultural adalah ide, gerakan, pembaharuan pendidikan dan proses pendidikan yang tujuan utamanya adalah untuk mengubah struktur lembaga pendidikan supaya siswa baik pria maupun wanita, siswa berkebutuhan khusus, dan siswa yang merupakan anggota dari kelompok ras, etnis, dan kultur yang bermacam-macam itu akan memiliki kesempatan yang sama untuk mencapaiprestasi akademis di sekolah. 
Adapun Howard berpendapat bahwa pendidikan multukultural memberi kompetensi multikultural. Pada masa awal kehidupan siswa, waktu banyak dilalui di daerah etnis dan kulturnya masing-masing. Kesalahan dalam mentransformasi nilai, aspirasi, etiket dari budaya tertentu, sering berdampak pada primordialisme kesukuan,agama, dan golongan yang berlebihan. Faktor ini penyebab timbulnya permusuhan antaretnis dan golongan. Melalui pendidikan multikultural sejak dini diharapkan anak mampu menerima dan memahami perbedaan budaya yang berdampak pada perbedaan usage (cara individu bertingkah laku); folkways (kebiasaan-kebiasaan yang ada di masyarakat), mores (tata kelakuan di masyarakat), dan customs (adat istiadat suatu komunitas). ${ }^{8}$

Dengan pendidikan multikultural peserta didik mampu menerima perbedaan, kritik, dan memiliki rasa empati, toleransi pada sesama tanpa memandang golongan, status,gender, dan kemampuan akademik. Bahwa pendidikan multikultural bermakna sebagai proses pendidikan cara hidup menghormati, tulus, toleransi terhadap keragaman budaya yang hidup di tengahtengah masyarakat plural, sehingga peserta didik kelak memiliki kekenyalan dan kelenturan mental bangsa dalam menyikapi konflik sosial di masyarakat.

Sementara itu Paul Gorski mendefenisikan pendidikan multikultural sebagai pendekatan progresif untuk mengubah pendidikan secara holistik dengan mengkritik dan memusatkan perhatian pada kelemahan, kegagalan, dan praktek diskriminatif di dalam pendidikan akhir-akhir ini. Keadilan sosial, persamaan pendidikan, dan dedikasi menjadi landasan pendidikan multikultural dalam pengalaman pendidikan agar semua siswa dapat mewujudkan semua potensinya secara penuh dan menjadikannya sebagai manusia yang sadar dan aktif secara lokal, nasional dan global. ${ }^{9}$

Lebih jauh, menurut Jose A. Cardinas (1975: 131), pentingnya pendidikan multikultural ini didasarkan pada lima pertimbangan: (1) incompatibility (ketidakmampuan hidup secara harmoni), (2) other languages acquisition (tuntutan bahasa lain), (3) cultural pluralism (keragaman kebudayaan), (4) development of positive self-image (pengembangan citra diri yang positif), dan (5) equilityof educational opportunity (kesetaraan memperoleh kesempatan 
pendidikan). Di pihak lain, Donna M. Gollnick (1983: 29) menyebutkan bahwa pentingnya pendidikan multikultural dilatarbelakangi oleh beberapa asumsi: (1) bahwa setiap budaya dapat berinteraksi dengan budaya lain yang berbeda, dan bahkan dapat saling memberikan kontribusi; (2) keragaman budaya dan interaksinya merupakan inti dari masyarakat Amerika dewasa ini; (3) keadilan sosial dan kesempatan yang setara bagi semua orang merupakan hak bagi semua warga negara; (4) distribusi kekuasaan dapat dibagi secara sama kepada semua kelompok etnik; (5) sistem pendidikan memberikan fungsi kritis terhadap kebutuhan kerangka sikap dan nilai demi kelangsungan masyarakat demokratis; serta (6) para guru dan para praktisi pendidikan dapat mengasumsikan sebuah perankepemimpinan dalam mewujudkan lingkungan yang mendukung pendidikan multikultural.

Merangkum berbagai defenisi tentang pendidikan multikultur di atas, maka secara lebih sederhana Banks dan Cherry menjelaskan, bahwa pendidikan multikultur dapat didefinisikan menurut tiga hal, yaitu ide atau konsep (idea or concept), gerakan reformasi (reform movement), dan proses berkelanjutan (ongoing process). Sebagai ide, pendidikan multikultur mengandung makna bahwa semua peserta didik, tanpa memperhatikan gender, status sosial, suku, rasa tau karakteristik budaya, wajib memperoleh kesempatan yang sama untuk belajar di sekolah. Sebagai gerakan reformasi, pendidikan multikultural dirancang untuk membuat perubahan di sekolah dan insitusi pendidikan sehingga seluruh peserta didik dari semua kelas sosial, gender, ras, dan kelompok budaya dapat memperoleh kesempatan yang sama untuk belajar. Sebagai proses berkelanjutan, pendidikan multikultur adalah proses terus menerus diterapkan di segala aspek pendidikan di sekolah dengan tujuan persamaan hak memperoleh pendidikan dan meningkatkan presetasi akademik untuk mencapai potensi tertinggi dirinya sebagai manusia (the highest potentials as human beings) yang mungkin tidak pernah tercapai sempurna tapi tetap terus diupayakan. Jadi, pendidikan multikultur merupakan reformasi sekolah yang komprehensif dan juga pendidikan dasar bagi semua siswa. Pendidikan multikultural menentang dan menolak rasisme dan segala bentuk diskriminasi di sekolah dan masyarakat. Pendidikan 
multikultur menerima dan menghargai pluralisme (etnik, ras, bahasa, agama, ekonomi, gender, dll) yang siswa, masyarakat dan guru wakili.

\section{Filsafat Pancasila Terhadap Pendidikan Multikultural di Indonesia}

Kajian filsafat Pancasila terhadap pendidikan multikultural akan terfokus pada nilai-nilai yang ada dalam Pancasila yaitu, Tuhan, yaitu sebagai kausa prima, Manusia, yaitu makhluk individu dan makhluk sosial, Satu, yaitu kesatuan memiliki kepribadian sendiri, Rakyat, yaitu unsur mutlak negara, harus bekerja sama dengan gotong royong dan Adil, yaitu memberi keadilan kepada diri sendiri dan orang lain yang menjadi haknya, adalah nilai-nilai dalam filsafat Pancasila. Filsafat Pancasila yang menjadi kajian pendidikan multikultural, menjadi sangat relevan dalam upaya menjadikan nilai-nilai yang terkandung dalam Pancasila sebagai perekat atau integrating force terhadap keragaman dan heterogenitas kehidupan sosial budaya. Tema filsafat Pancasila dalam sila-sila Pancasila untuk pendidikan Multukultural, dapat dipaparkan sebagai berikut:

\section{Sila pertama, Ketuhanan Yang Maha Esa:}

1. Agama diajarkan dalam konteks pendidikan multikultural sebagai yang tidak terpisahkan dengan makna ke-Tuhan-an. Manusia memiliki hubungan sebab akibat yang langsung dengan Tuhan sebagai kausa prima (sebab pertama).

2. Nilai-nilai ke-Tuhanan-an diajarkan dalam pendidikan multikultural sebagai motivasi dasar yang paling penting dalam segala aspek penyelenggaraan negara. Tidak dibenarkan menyimpang dari ketentuan-ketentuan yang digariskan oleh Tuhan.

3. Memaknai Tuhan dalam pendidikan multikultural sebagai suatu kekuatan keyakinan (bahwa Tuhan ada dalam objektvitasnya).

4. Pendidikan multikultural mengajarkan bahwa, Manusia menjadi mandat Tuhan untuk terlibat dalam lembaga-lembaga masyarakat.

5. Keaneragaman dalam negara Indonesia adalah pemberian Tuhan. Pendidikan multikultural mesti memaknai keanekaragaman sebagai bagian yang tidak dapat dipisahkan walaupun memiliki perbedaan. 
6. Pancasila sebagai dasar negara, dalam penerapan untuk pendidikan multikultural mesti ditanamkan sebagai suatu azaz kerohanian, azaz moral dan sebagai sumber nilai.

7. Mengkaji dalam pendidikan multikultural bahwa, Negara Indonesia tidak memaksakan agama dan kepercayaan kepada Tuhan Yang Maha Esa karena itu merupakan suatu keyakinan, suatu hak asasi yang paling fundamental.

Sila kedua, Kemanusiaan yang adil dan beradab:

1. Pendidikan multikultural haruslah mengkaji bahwa, Kemanusiaan yang adil dan beradab, dimaknai juga oleh sila pertama sampai sila kelima dari Pancasila.

2. Kajian pendidikan multikultural terhadap manusia, haruslah terfokus pada pemahaman bahwa manusia memiliki kodrat, sebagai mahluk Tuhan, sebagai pribadi dan dapat hidup sebagai mahluk sosial.

3. Perilaku kemanusiaan dalam pendidikan multikultural, haruslah perilaku yang watak berlaku berhati-hati, dimana setiap perbuatan haruslah merupakan hasil pertimbangan akal, rasa dan kehendak, juga secara selaras. Watak keadilan, watak kesederhanaan dan watak keteguhan.

4. Pendidikan multikultural, sebaiknya mendefenisikan hakikat adil dan beradab sebagai, adil terhadap diri sendiri, adil terhadap sesama manusia lainnya dan adil terhadap Tuhan. Beradab dengan perilaku sebagai mahluk individu, sosial, dan mahluk Tuhan.

\section{$\underline{\text { Sila ketiga, Persatuan Indonesia }}$}

1. Memaknai sila ketiga dengan keempat sila lainnya dalam Pancasila. Kata Satu adalah mutlak dan tidak terpecah atau menjadi bagian-bagian. Satu adalah tunggal dan satu yang tersusun dari membangun suatu keutuhan.

2. Pendidikan multikultural haruslah mendefenisikan Persatuan Indonesia, sebagai wujud persatuan wilayah, bangsa dan negara Indonesia. Tidak memiliki sifat keterpisahan. 
3. Konteks pendidikan multikultural lebih terarah pada kehidupan persatuan Indonesia yang memiliki tujuan bersama, memiliki asas kekeluargaan, tolong menolong dengan dasar keadilan sosial dan kepentingan bersama merupakan keutamaan dalam hidup berbangsa dan bernegara.

4. Keanekaragaman harus didefeniskan dalam pendidikan multikultural sebagai suatu daya tarik untuk menjaga kesatuan bangsa dan negara Indonesia. Artinya wujud perilaku keanekaragaman yang diajarkan dalam pendidikan multikultural adalah membangun kerja sama untuk memelihara persatuan bangsa dan negara.

Sila keempat,Kerakyatan yang dipimpin oleh Hikmat Kebijaksanaan dalam permusyawaratan perwakilan:

1. Pendidikan multikultural haruslah menjiwai sila keempat juga merupakan kesatuan dengan sila-sila yang lainnya.

2. Sila keempat memiliki multiklutural yang berintikan demokrasi yang kekeluargaan, gotong royong, keadilan sosial dari oleh rakyat secara bersamasama.

3. Rakyat sebagai bagian dari multikultural memiliki kedaulatan sebagai pendukung dan penyelenggaraan kepentingan bangsa dan negara.

4. Kesejahteraan dan kebahagiaan rakyat, dalam pendidikan multikultural terukur pada hasil yang bernilai untuk meningkatkan harkat dan martabat seluruh masyarakat.Termasuk kelangsungan hidup dan kesejahteraan generasi mendatang.

Sila kelima, Keadilan Sosial bagi Seluruh Rakyat Indonesia:

1. Sila kelima senantiasa merupakan suatu kesatuan dengan sila-sila yang mendahuluinya,

2. Pendidikan multikultural sebaiknya menjiwai sila kelima dalam konteks manusia sebagai mahluk sosial dalam suatu keseimbangan berdasarkan hakikat adil. 
3. Mengkaji hakikat keadilan sosial dari pendidikan multikultural, maka keadilan diperuntukan bagi manusia sebagai yang memiliki kodrat, manusia sebagai pendukung keadilan sosial.

4. Keadilan dalam pendidikan multikultural membutuhkan keadilan hubungan manusia dengan Tuhan dan manusia dengan manusia. Membangun hidup kebersamaan antar sesama manusia.

5. Pendidikan multikultural dalam mendefenisikan keadilan sosial terkait juga dengan pemahaman yang benar tentang hak dan kewajiban. Bahwa hak dan kewajiban adalah kodrat bagi manusia dan harus ada secara bersama-sama.

\section{PENUTUP}

Kajian filsafat Pancasila terhadap Pendidikan Multikultural di Indonesia memberikan wacana-wacana tersendiri terhadap makna dan nilai pendidikan multikultural. Filsafat Pancasila memaknai pendidikan multikultural sebagai proses pendidikan untuk menumbuhkan kemampuan cara hidup menghormati, tulus, dan toleran terhadap keragaman budaya yang hidup di tengah-tengah masyarakat plural. Filsafat Pancasila memberikan nilai-nilai pendukung nilainilaibagi pendidikan multikultural di Indonesia yaitu bahwa bangsa Indonesia adalah yang berketuhanan, yang berkemanusiaan, yang berpersatuan, yang berkerakyatan dan berkeadilan sosial. Pendidikan multikultrual dapat menjabaran nilai-nilai pendukung filsafat Pancasila dalam sikap Pengakuan, penerimaan dan penghargaan atas nilai-nilai Pancasila itu dan dapat diwujudkan dalam sikap, tingkah laku, dan perbuatan bangsa Indonesia sehingga mencerminkan sifat khas sebagai Manusia Indonesia

\section{Catatan akhir}

${ }^{1}$ Imam Barnadia. Filsafat Pendidikan: Sistem dan Metode. Yogyakarta: Penerbit Andi Offset. 1994. Hal 11

${ }^{2}$ Notonegoro. Beberapa Hal mengenai Falsafah Pancasila. 1975. Hal 24

${ }^{3}$ Notonegoro. Pancasila Dasar Falsafah Negara. Jakarta: Bhina Aksara. 1974. Hal 19.

${ }^{4}$ Notonegoro. Pancasila Dasar Falsafah Negara,... h.16 
${ }^{5}$ Notonegoro. Pancasila Dasar Falsafah Negara, ... h. 18

${ }^{6}$ Banks James. Introduction to Multicultural Education. Boston:, Mass: Perason. 2008. H. 10

${ }^{7}$ G.R. Howard. Whites in Multicultural Education-Rethiniking Our Role. 1993. Phi-Delta Kppan. 1(75), h. 36-41.

${ }^{8}$ Paul Gorski. Multicultural Education and The Internet: Intersections and Intergrations. Boston,MA:McGraw Hill. 2000. h 9

9 Paul Gorski. Multicultural Education and The Internet: Intersections and Intergrations. Boston,MA:McGraw Hill. 2000. h 9

\section{DAFTAR PUSTAKA}

Banadia I. (1994). Filsafat Pendidikan: Sistem dan Metode. Yogyakarta: Penerbit Andi Offset.

Gorski.P. (2000). Multicultural Education and The Internet: Intersections and Intergrations. Boston,MA:McGraw Hill. 2000. Hal 9

Howard. G.R. Howard. (1993). Whites in Multicultural Education-Rethiniking Our Role. Phi-Delta Kppan. 1(75), 36-41

James. B. (2008). Introduction to Multicultural Education. Boston:, Mass: Pearson.

James. B and Cherry A. (1997). Multicultural Education Issues and Perspectives. Needhaam Heights, MA: Allyn and Bacon.

Morris. V. C. (1963). The Philosophy in Education in Becomin on Educator. Boston, Houghthon: Mifflin Company.

Notonegoro. (1975). Beberapa Hal mengenai Falsafah Pancasila.

Notonegoro. (1974). Pancasila Dasar Falsafah Negara. Jakarta: Bhina Aksara. 